\title{
Turning Hild's Sculptures into Single-Sided Surfaces
}

\author{
Carlo H. Séquin 1
}

EECS Computer Science, University of California, Berkeley 94720, CA, USA; sequin@berkeley.edu

Received: 15 December 2018; Accepted: 17 January 2019; Published: 25 January 2019

Abstract: Eva Hild uses an intuitive, incremental approach to create fascinating ceramic sculptures representing 2-manifolds with interesting topologies. Typically, these free-form shapes are two-sided and thus orientable. Here I am exploring ways in which similar-looking shapes may be created that are single-sided. Some differences in our two approaches are highlighted and then used to create some complex 2-manifolds that are clearly different from Hild's repertoire.

Keywords: Eva Hild; 2-manifolds; computer-aided design; 3D printing

\section{Eva Hild's Sculptures}

Eva Hild is a Swedish artist [1], who creates large ceramic sculptures (Figure 1) in an intuitive, incremental process [2,3]. I have been fascinated by her work for several years [4], before I was finally able to meet her in her studio in Sparsör, Sweden in July 2018 (Figure 1b).

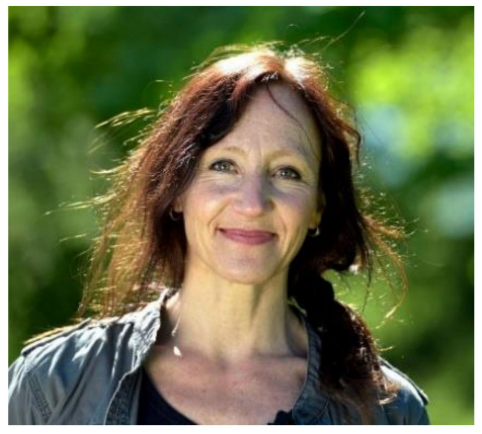

(a)

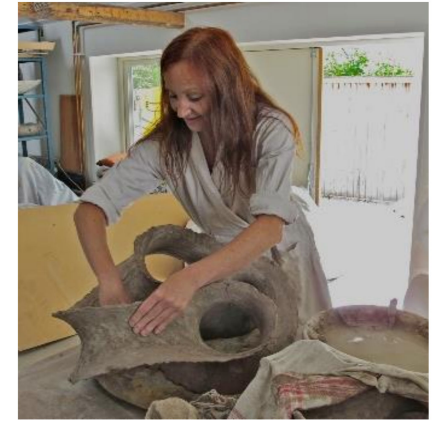

(b)

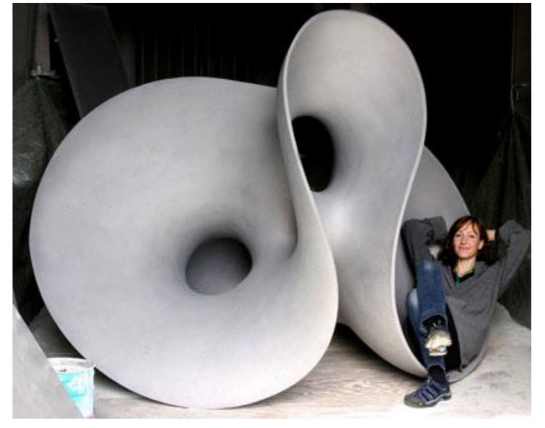

(c)

Figure 1. Eva Hild: (a) A portrait; (b) working in her studio; and (c) with the sculpture Hollow [1].

Her creations are typically thin surfaces, which may take on the structure of bulbous outgrowths in plant-like assemblies (Figure 2a), or configurations of intricately nested funnels (Figure $2 b$ ). These surfaces may be bordered by simple circular openings or by long, sensuously undulating curved rims, which are connected by a system of crisscrossing tunnels (Figure 2c). These sculptures invite mental explorations, raising questions such as: how many tunnels are there? How many separate rims are there? Is this a 1-sided or 2-sided surface? These sculptures also have inspired me to create similar shapes [4]. I do not possess the skills to create large ceramic pieces myself, so I have tried to create computer-aided design (CAD) models of such surfaces, and then have realized the more promising ones as 3D printed models. My students and I found it rather difficult to capture Hild's sculptures in CAD tools such as Blender [5] or Maya [6]. We had difficulties in defining the proper topologies-often just starting from a few photographs found on the World Wide Web. We also found it difficult to fine-tune these topologically correct models, so that they would reproduce the organic 
flow and natural elegance of Hild's creations. We thus ended up developing some additional modeling tools to make the design of such shapes less cumbersome and frustrating.

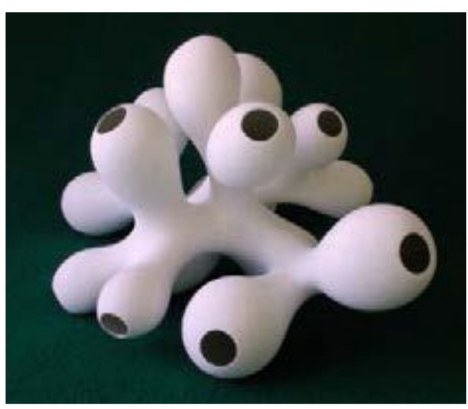

(a)

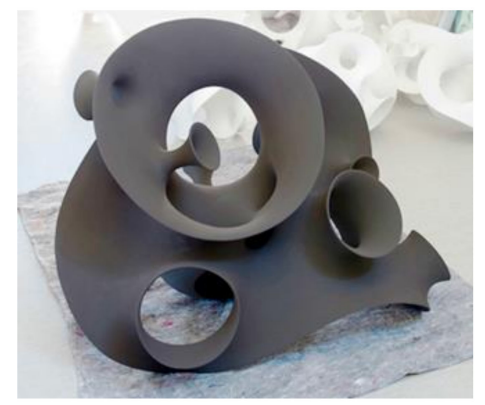

(b)

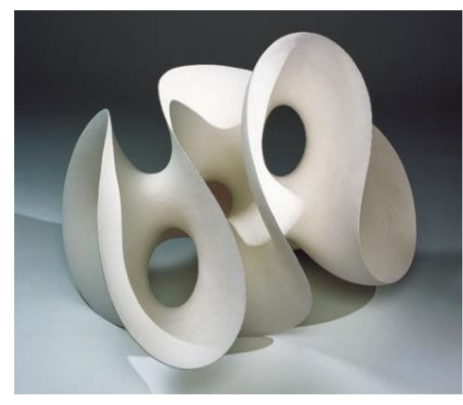

(c)

Figure 2. Eva Hild's ceramic creations [1]: (a) a bulbous surface with oculus-like openings; (b) various nested funnels; and (c) hyperboloid tunnels and undulating rims.

To place the results of this paper into proper perspective, I start with a brief review of the developments that led me to this current investigation and some of the many other contributions in this domain, made by artists as well as mathematicians.

\section{Background and Previous Work}

For much of my life I have been fascinated by abstract, geometrical sculpture. As a student, some of my heroes were Alexander Calder, Naum Gabo, and Max Bill. In the 1980's, when I started to teach courses in computer graphics and computer-aided design [7], I employed the help of such techniques to analyze and synthesize topologically interesting sculptural shapes. The key stimulation for my strong involvement in this field came from my interaction with Brent Collins [8]. This connection was prompted by an analytical write-up by George Francis [9] in a special issue on visual mathematics in Leonardo in 1992, which clearly showed the connection between the intuitive sculptural work of Collins and the geometry of minimal surfaces, the topology of interconnected tunnels and handles, and basic knot theory. I started to write a specialized, parametrized computer program, called Sculpture Generator I (Figure 3a) [10] that allowed me not only to capture some inspiring shapes created by Collins, but also enabled me to make several derivative designs that seemed to belong to the "same family". Collins was fascinated by this prospect and was eager to sculpt additional, more complex shapes by relying heavily on my detailed, computer-generated printouts. Our first two collaborative pieces were Hyperbolic Hexagon II (Figure 3b) [11] and Heptoroid, (Figure 3c) [12], both of which were a generalization of a 6- or 7-story Scherk-Tower [13] bent into a closed, possibly twisted loop. Heptoroid was particularly exciting to us, because it introduced a non-orientable, single-sided surface with a heavily knotted border.

Sculpture Generator I was a very specific program that could only generate sculptures based on Scherk's Second Minimal Surface [13]. To capture any other one of Collins' inspirational sculptures, such as Pax Mundi (Figure 4a) [14], I needed a new program with different geometrical primitives: in particular, versatile progressive sweeps that would allow me to move an arbitrary cross section along any 3D sweep path. This gradually led to the development of the Berkeley SLIDE program (Figure 4b) [15]. This modeling tool has a variety of parameterized geometric modules that can be combined in many different ways. By using its sweep construct, I was able to capture Pax Mundi and design a large collection of Viae Globi sculptures [16], in which a ribbon travels along the surface of a sphere. With this program we scaled up Pax Mundi, and with the help of Steve Reinmuth [17] realized it as a large Bronze sculpture [18]. The SLIDE program then allowed us to create other Viae Globi sculptures, some of which had knotted sweep paths, such as Music of the Spheres (Figure 4c) [19]. 


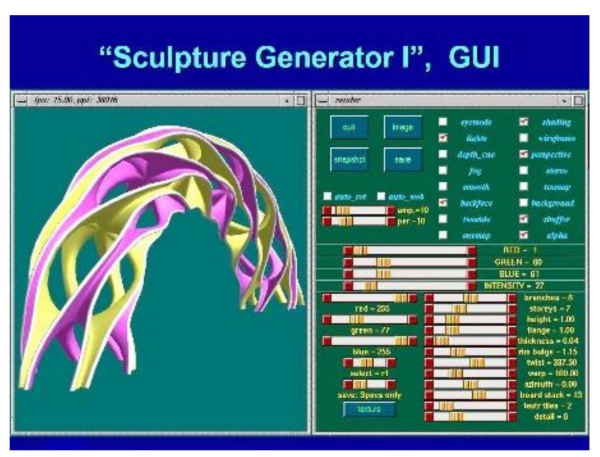

(a)

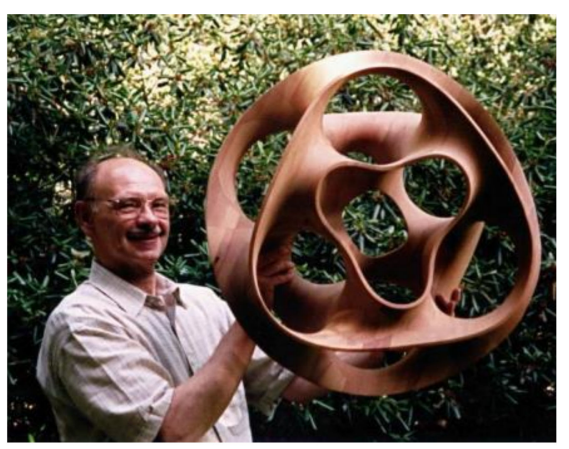

(b)

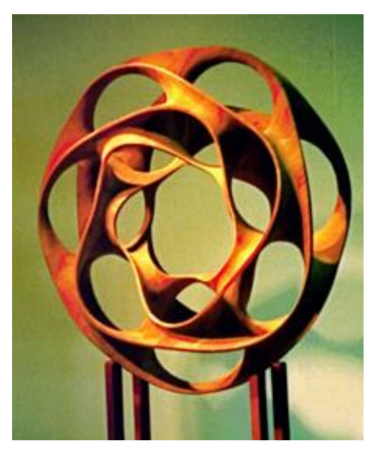

(c)

Figure 3. Sculpture Generator I: (a) The user interface; (b) Hyperbolic Hexagon II; and (c) Heptoroid.

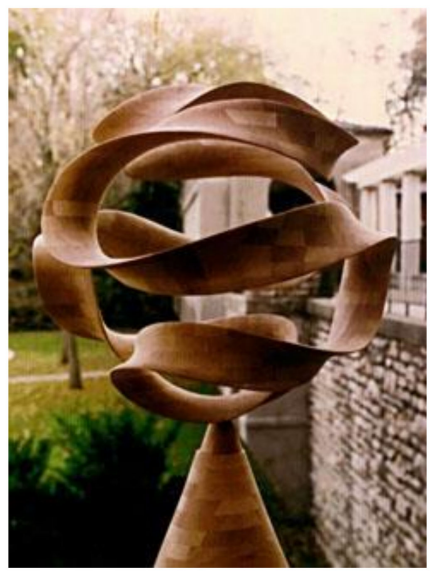

(a)

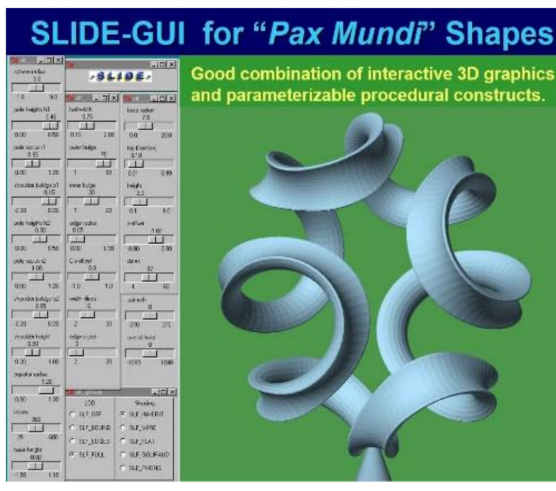

(b)

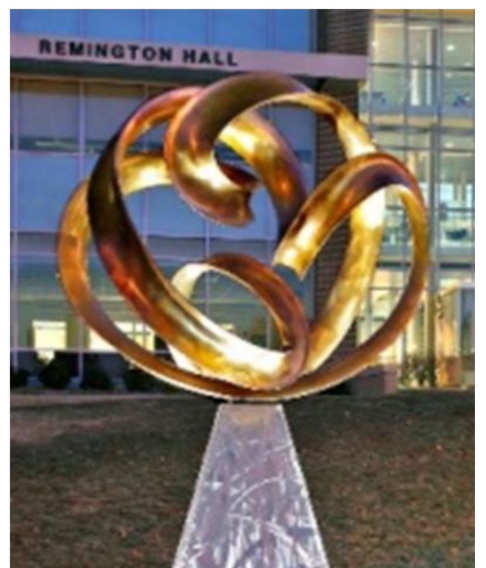

(c)

Figure 4. Roads on a Sphere: (a) Pax Mundi; (b) SLIDE user interface; and (c) Music of the Spheres.

Collins created his inspirational sculptures in an intuitive way, driven by the aesthetics of the emerging form, not by thinking about mathematics or topological issues. Other artists start out quite consciously with mathematics on their mind. Helaman Ferguson [20] has created stone and bronze sculptures based on mathematical equations, given knot structures, or topologically intriguing surfaces [21]. George Hart [22] is often driven by some high-order symmetry group and then finds ways to interlink many identical pieces in an intricate manner, while maintaining the envisioned symmetry [23]. He relies on computer-aided tools to define these shapes [24], and even to fabricate them with a computer-driven paper cutter [25]. A similar way of using CAD tools also enables the work of many other artists, such as Bathsheba Grossman [26], Vladimir Bulatov [27], Rinus Roelofs [28], and Hans Schepker [29]. Charles O. Perry [30,31], even though he often starts by defining crucial elements of his sculpture by shaping physical materials such as steel cables, is also quite conscious of the mathematical underpinnings of some of his sculptures [32,33].

For other authors, the key motivation is to generate a visualization of some mathematical concept, rather than creating a piece of art. Jarke van Wijk uses computer graphics to generate the Seifert surfaces supported by mathematical knots [34]. His demonstration tool is readily available on the web [35], and by choosing the right smoothing option, one can produce visualization models that can also stand on their own as pleasing sculptural shapes. Other mathematical concepts, where visualization models can readily turn into art, concern non-orientable surfaces—such as Boy's surface (Figure 5a) $[36,37]$ or Klein bottles (Figure 5b) [38,39] —and the depiction of regular maps [40-42], regular meshes [43,44], woven surfaces [45,46], knot theory [47-49], or high-genus objects (Figure 5d) [50,51]. 


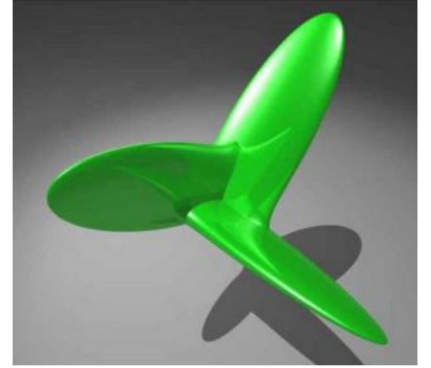

(a)

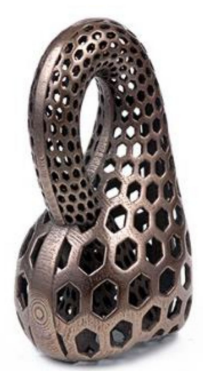

(b)

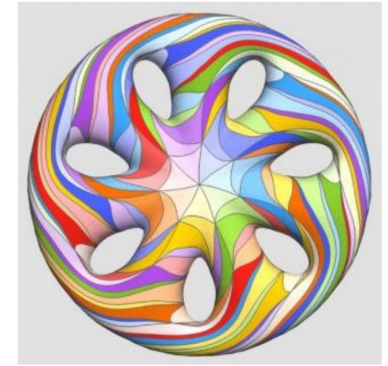

(c)

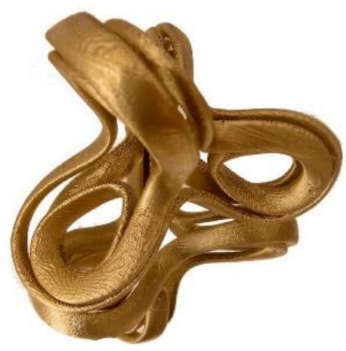

(d)

Figure 5. Mathematical visualizations as art: (a) a Boy's surface [36]; (b) a Klein bottle [38]; (c) a regular map [40]; and (d) a high-genus object [50].

For most of the above mathematical concepts and mentioned artists, Berkeley SLIDE [15] or readily available programs such as Rhino3D [52] or TopMod [53] are adequate tools to capture the corresponding models, because these shapes typically can be depicted with a few clearly defined geometrical primitives. This is true even for the works of artists like Brent Collins [8], Keizo Ushio [54], or Bob Longhurst [55], who intuitively sense some underlying mathematical principles, but do not explicitly use a mathematical formulation or a computer program to define their shapes. Also, the "D-Forms" introduced by Tony Wills [56] or the developable surfaces by Ilhan Koman [57,58] have a clearly defined geometrical structure that can be captured in a procedural specification.

Eva Hild's work [1], on the other hand, presents a new modeling challenge. Her ceramic surfaces are truly free-form [2,3], and if the underlying topology would allow for some regularity or symmetry, Hild would deliberately remove it [4]. Thus, the predefined modules in SLIDE are no longer sufficient, and modeling her work requires some additional capabilities, which will be described in Section 4 . Moreover, as discussed in Sections 7 and 8, I faced another novel challenge: how to make a significant topological change to some intuitively conceived geometries, while keeping the visual look-and-feel the same.

\section{Classification of 2-Manifolds}

From a mathematician's point of view, Eva Hild's sculptures ( Figures 1 and 2) are smooth 2-manifolds with one or more borders [59]. As a brief reminder: every interior point in a 2-manifold has a neighborhood that is topologically equivalent to a small disk; and every border point has a neighborhood equivalent to a half-disk (Figure $6 a, b$ ). Branching of surface sheets, as in the spine of a book, is not allowed. Thus, if the 2-manifold surface is finely tessellated, then every facet edge is used by either one or by two adjacent facets.

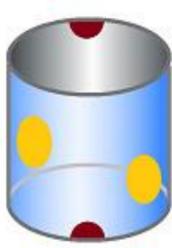

(a)

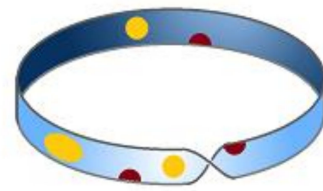

(b)

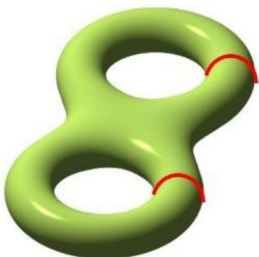

(c)

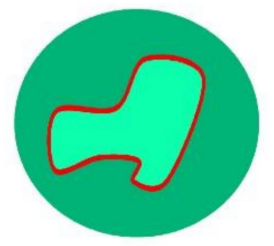

(d)

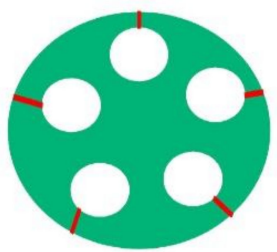

(e)

Figure 6. Various 2-manifolds: (a) a 2-sided cylinder; (b) a 1-sided Möbius band; (c) a genus-2 handle body; (d) a disk: Euler characteristic $\chi=1$, genus $g=0$; and (e) a disk with 5 holes and 5 cuts.

All possible 2-manifolds can be classified by just three numbers: $b$, the number of borders; $s$, its sidedness; and its connectivity described by its genus, $g$. For a given 2-manifold, the number of borders is easily determined: We start with some border point; we follow along this rim line until we arrive back at the starting point; we mark this rim as 'counted'; and we repeat this until there are no further unmarked borders. To determine the sidedness, s, we start with an interior point and paint its 
neighborhood with a flood-filling algorithm; we continue this process as far as we can without ever stepping across a border line. If, in the end, all surface points have been painted, then the surface is single-sided, and also non-orientable. If only half of all surface areas have been covered, then the surface is two-sided, and orientable.

The connectivity of a 2-manifold is more difficult to determine. Its genus, $g$, is defined as the maximal number of closed curves that can be drawn on the 2-manifold without dividing its surface into two separate "countries." But how do we know that we have indeed found the maximal number of such curves? One more practical approach is to close off all punctures in the surface by gluing in disk-like surface patches into any open border loops, as long as this can be done without creating any self-intersections. If this results in a well-behaved handle-body (Figure 6c), we count the number of its handles or tunnels to find its genus. As an alternative, we may make cuts through the 2-manifold from some border point to another border point until the resulting 2-manifold has acquired the topology of a single disk without any holes (Figure 6d). If there are still interior holes in the surface, we need to make additional cuts from the current disk borders (Figure 6e). However, we must not split the surface into separate pieces; everything must remain connected. We know that the Euler characteristic, $\chi$, of a disk is 1 , and that every cut adds 1 to $\chi$. Thus, we derive that the original manifold must have had an Euler characteristic of 1 minus the number cuts that we have made. The Euler characteristic and genus are then related according to the following formula:

$$
\text { Genus }=(2-\chi-b) / \mathrm{s},
$$

An intriguing discovery is that the 2-manifolds created by Eva Hild [60] show a wide variety in their number of borders and in their genus-but they are all double-sided! Later, I will speculate how this may have come about. Furthermore, I will also try to transform some of these sculptures into single-sided 2-manifolds, while making only small style changes.

\section{My Modeling Approach}

After some experimentation, I found that a good way for capturing the basic geometry of Hild's sculptures is to locate some defining key features, in particular, "rims", "funnels", and "tunnels". These features have been marked on a few sculptures in Figure 7. These features typically form the starting point in my attempts to model these geometries. They are placed in appropriate locations in 3D space, and the surface is then constructed, facet by facet, between points on these border curves in an interactive manner through a graphical user interface. Our home-brewed modeling system, Berkeley SLIDE [15], developed two decades ago, is well suited to define and place such key features in a parameterized manner. It provides a slider for every parameter, so that complex configurations of such features can be fine-tuned in an interactive manner. Unfortunately, it has no interactive capabilities to form the connecting surface between these features. Moreover, SLIDE cannot handle single-sided surfaces in operations such as surface smoothing and offsetting.

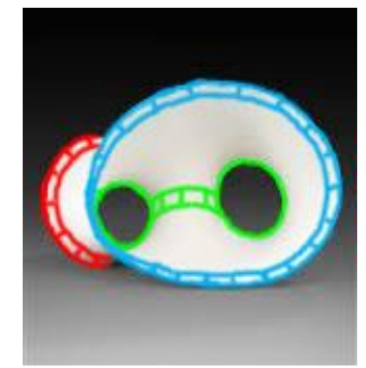

(a)

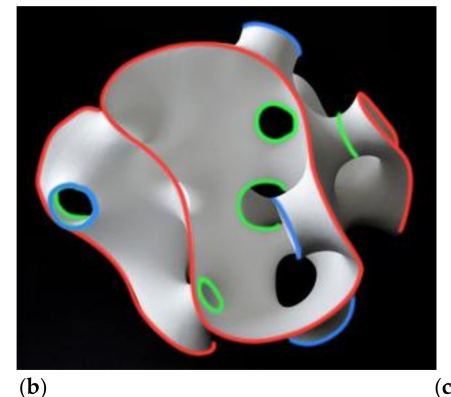

(b)

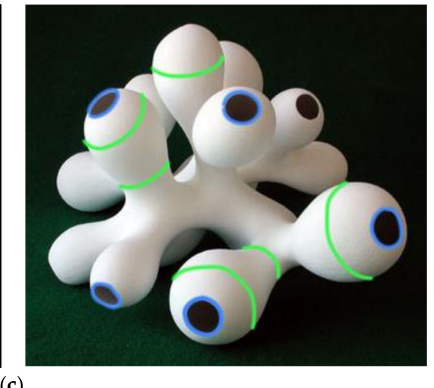

(c)

Figure 7. Key features marked on some Hild sculptures: red indicates rims; blue indicates funnels; and green indicates tunnels. 
To overcome these shortcomings, my research students have helped me to create a new CAD environment, called NOME (Non-Orientable Manifold Editor) [61,62]. Just like SLIDE, this program allows the procedural placement of the parameterized key features though a simple text interface. It then provides crucial editing capabilities to form a surface between these features.

Moreover, there are pre-programmed generators for funnels and tunnels with all their defining variables. Once these features have been placed reasonably well, the user constructs the connecting mesh in a point-and-click manner. The user may select some number, $n$, of vertices and then create a $n$-sided facet (typically irregular and non-planar) spanned by those vertices. The key characteristic is that this facet behaves like a rubber sheet, staying attached to the different tunnels, funnels, or rims, as these elements are repositioned and re-shaped. The parametrization of the key features remains active through the entire design process. Even after subdivision smoothing has been applied and offset surfaces have been generated, the parameters can still be changed, and the user will immediately see the effect that this has on the final geometry to be sent to the 3D printer. This is a crucial capability of NOME that we have found difficult to implement in other CAD tools.

I will now describe my current modeling approach with the example of a reconstruction of two relatively simple sculptures by Eva Hild. The first one is Interruption [60]; Figure 7a shows a bottom view of this sculpture, and Figure $8 \mathrm{a}$ is a side view. In Figure 8b, I placed a (blue) funnel at the bottom, fitted a (red) free-form B-spline curve along the top rim, and inserted three (greenish) tunnels to define the internal passages. Identifying, defining, and placing these key features is a crucial first step in creating a replica of an existing sculpture. So far, we have not been able to think of an automated process that would extract that information from a few images. Being able to adjust the parameters that define these features through the very end of the design process is thus an important capability for obtaining good-looking results.

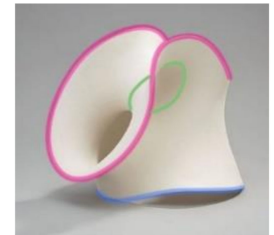

(a)

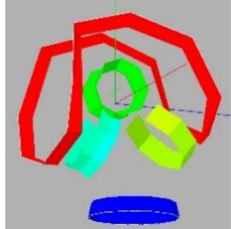

(b)

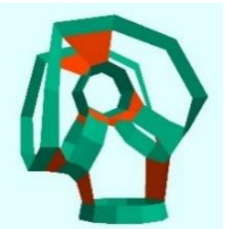

(c)

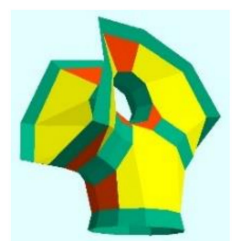

(d)

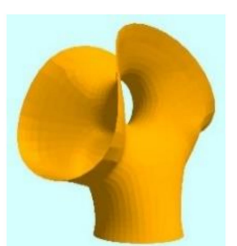

(e)

$(\mathbf{f})$

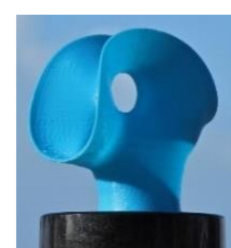

Figure 8. Interruption: (a) Hild's sculpture with key features marked; (b) key features modeled; (c) first quad faces added; (d) the connecting mesh; (e) the subdivision surface; and (f) the resulting 3D print.

The next step is to specify the polyhedral mesh components that properly connect these feature geometries to one another. First, a few connecting quads are introduced, shown in red in Figure 8c; then the various mesh patches are filled in, shown in yellow in Figure 8d. This composite mesh is subjected to three or four steps of Catmull-Clark subdivision [63] to produce a smooth, tangent-continuous surface (Figure 8e). This smoothing process has been robustly implemented in SLIDE as well as in NOME, and it typically produces soap film-like surfaces for polyhedral models with a variety of facets. The best results are obtained when the starting mesh is composed mostly of quadrilaterals that all have about the same edge length. Once we have a pleasing looking mesh, which is tessellated finely enough to display the desired level of smoothness, NOME generates two offset surfaces that lie at a distance $t / 2$ on either side of the subdivision surface. Additionally NOME generates a set of rectangular facets along all border curves to connect the two offset surfaces into a water-tight boundary, creating a physical object of thickness, $t$, which then can be fabricated on a 3D printer (Figure 8f).

Even at this late stage in the design process, the various parameters are all still fully in effect. For instance, by raising the position of the blue funnel, the tubular base of the sculpture can be shortened, or by changing the diameter or length of any of the tunnels, the corresponding hole-geometries can be fine-tuned. This final geometry is then captured as an STL-file [64]. In this 
procedure, the facets of the boundary representation are split into triangles, which are then listed with their three vertices and their face normal. This is a rather wasteful description, and the resulting files are typically tens of Megabytes in size; it is, however, a format that is understood by all 3D printers.

Creating good 3D models represents additional challenges. 3D printers come with their own software for handling the tricky task of constructing adequate scaffolding structures for supporting hollow or overhanging geometries as needed. However, print orientation, print speed, and fill-in density must still be decided by the user, and they can strongly affect printing time and the quality of the print.

\section{Modularity: Deriving New Topologies}

The CAD tools described above, allow me to now focus on designing new geometries inspired by Hild's creations. In a first demonstration, I started from Hild's Whole (Figure 9a,b). To model this structure, I created a new auxiliary geometrical shape, a cross-tunnel (Figure 10a). Two instances of this new feature were then surrounded with an undulating 3-period Gabo curve [65] to form the complete feature model (Figure 9c) defining my version of this sculpture. Figure 9d shows the resulting 3D print. In contrast to Hild's sculpture, which has an organically flowing, slightly irregular shape, my model exhibits strict " $\mathrm{C}_{2 \mathrm{~h}}$ symmetry" (Schönflies notation), also known as " $2^{* \prime}$ symmetry (Conway notation), featuring a vertical mirror plane (most easily visible in Figure $9 \mathrm{c}$ ) and a horizontal $\mathrm{C}_{2}$ rotation axes (Figure 9d).

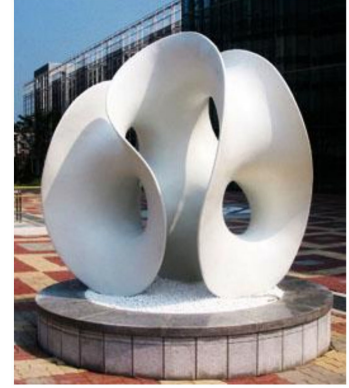

(a)

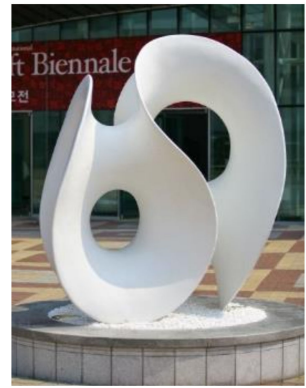

(b)

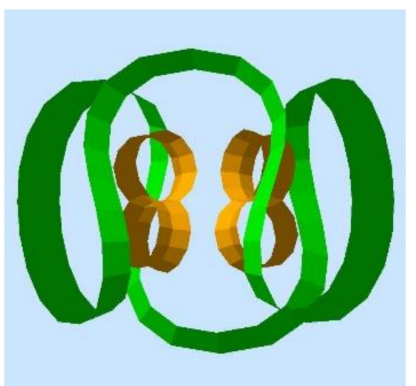

(c)

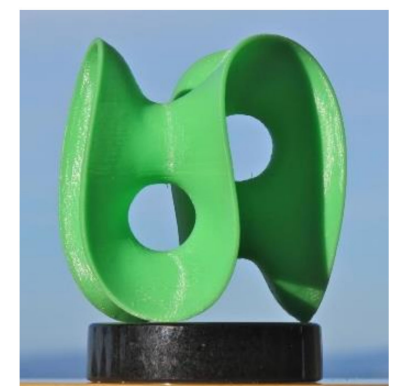

(d)

Figure 9. Modeling Whole: (a,b)two views of Hild's sculpture; (c) skeleton computer-aided design (CAD) model; (d) 3D printed model.

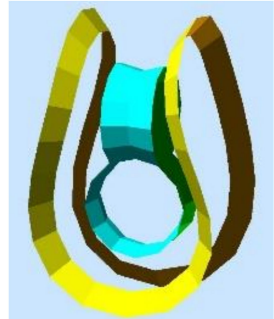

(a)

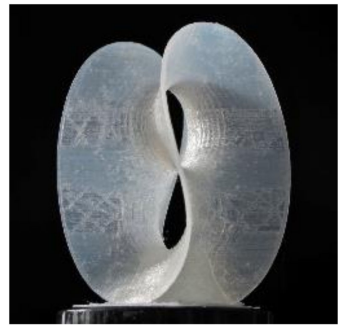

(b)

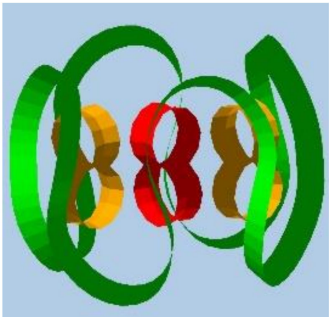

(c)

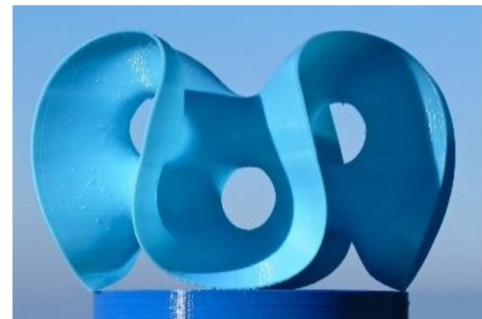

(d)

Figure 10. Wrapped Cross-Tunnels: (a,b), a one cross-tunnel sculpture; and (c,d) a three cross-tunnel sculpture.

These same basic features can now be readily used in different configurations to make new derivative geometries. Figure 10a,b show what happens when I use just a single cross-tunnel and augment it with a simple 2-period Gabo curve (as found in the seam of a baseball). In yet another variation, I have placed three such cross-tunnels side-by-side and wrapped a 4-period Gabo curve around them (Figure 10c). NOME [62] was used to fill the voids between the Gabo ribbon and the inner core formed by the three cross-tunnels. The resulting 3D printed object is shown in Figure $10 \mathrm{~d}$. 
Figure 11 shows a sculpture that results, when three cross-tunnels are placed in a circular arrangement, so that the lower tunnels point in radial directions. This inner core is surrounded by a 3-period Gabo curve, and an additional large funnel is placed at the bottom of this arrangement to produce a stand for the sculpture. Figure 11a shows the key features placed in 3D space. To this I then add one third of the connecting control surface (Figure 11b). Two copies, rotated by $\pm 120^{\circ}$, result in the complete topological model. After three levels of Catmull-Clark-subdivision [63] and offset surface generation (Figure 11c), a corresponding STL file is saved and sent to a 3D printer (Figure 11d).

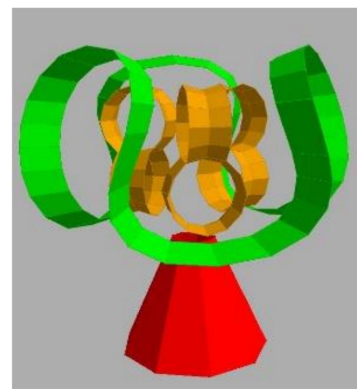

(a)

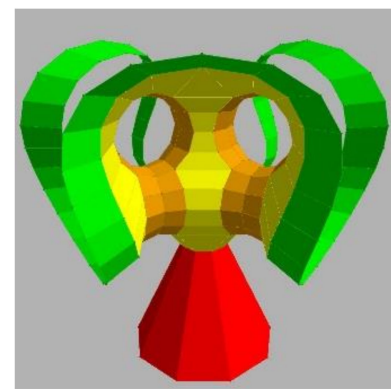

(b)

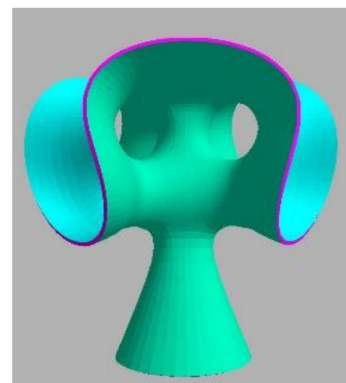

(c)

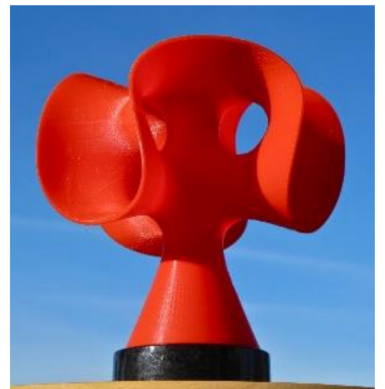

(d)

Figure 11. The Lighthouse: (a) the key features; (b) $1 / 3$ of the control surface is added; (c) model after smoothing and offsetting; and (d) the resulting 3D printed object.

This model has overall 6-fold $C_{3 v}$ symmetry. Eva Hild would not create such geometries with perfect symmetry. Even if the topology offers some inherent symmetry, she would deliberately deform the geometry to break that symmetry and obtain a more organic, natural look. A drastic example of this can be found in Wholly, a metal sculpture located in the town of Borås, Sweden.

\section{Wholly-A More Challenging Modeling Task}

Free-form surfaces, such as Wholly (Figure 12a), offer a bigger modeling challenge. The difficulties in capturing the shape of this piece demonstrate the need for a well-selected procedural description of the basic geometry. The first step is to figure out the topology and connectivity of the given surface. Here it is captured in the relatively simple model shown in Figure 12b. This is an orientable surface of genus 4 with a single border. Geometrically, it can be seen as a chain of eight side-by-side tunnels separated by seven saddle surfaces. The bottom half shows a simple polyhedral model that yields the proper topology for Wholly. However, it would be overwhelming to ask the user to move all 72 vertices of this model into the appropriate locations to recreate Wholly. Thus, we need a higher level of control!

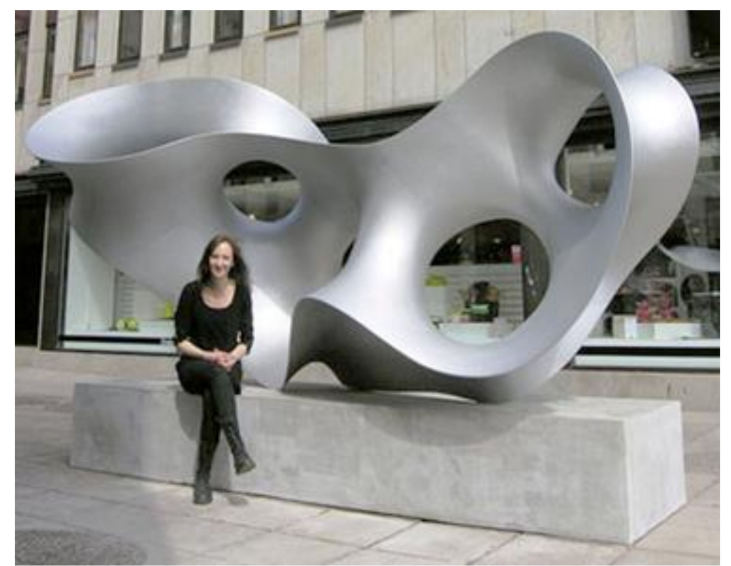

(a)
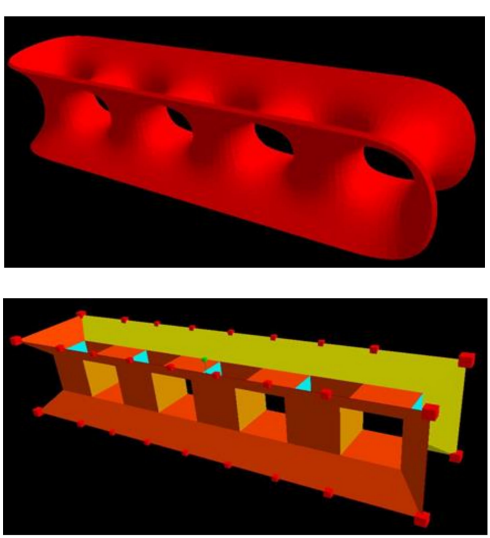

(b)

Figure 12. Hild's Wholly: (a) the sculpture in Borås; (b) models capturing its topology. 
For this model, I defined nine cross-sectional planes, seven of which go through the walls between pairs of adjacent tunnels, and two more that are located at the two ends of the chain. Each of these sections can now be non-uniformly stretched, rotated, and shifted. A result of such coordinated edits is shown in Figure 13a. All of the nine cross sections remains planar and symmetrical, but their sizes and positions define the shapes and orientations of the tunnels between them. The shape in Figure 13b starts to show the look and feel of Hild's Wholly sculpture.

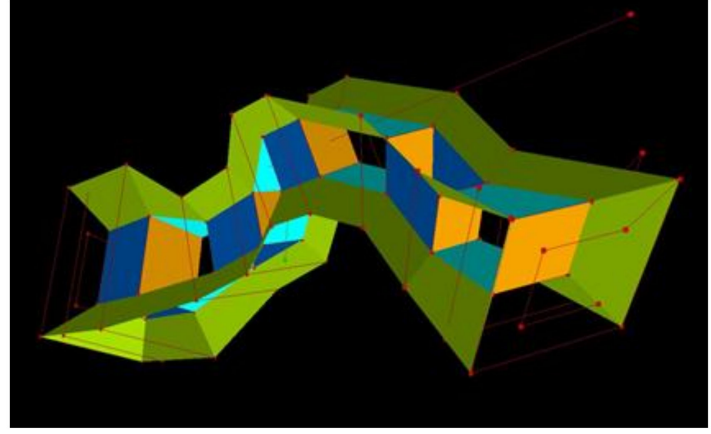

(a)

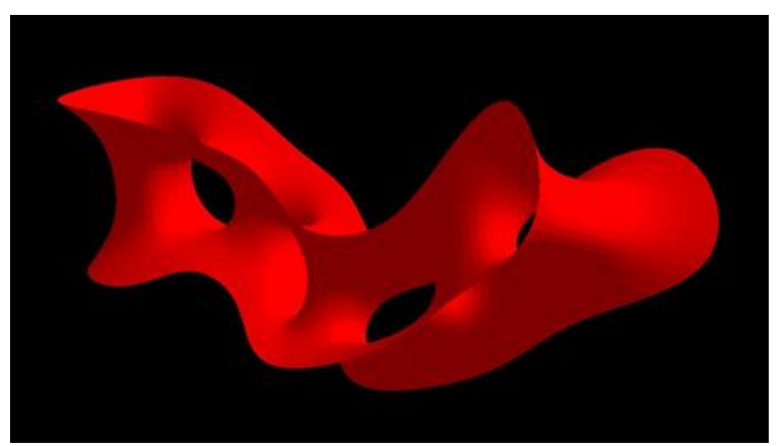

(b)

Figure 13. Modeling Wholly: (a) a deformed control mesh; (b) the resulting shape after smoothing.

The described approach was not yet satisfactory for modeling this particular sculpture. A key difficulty was keeping all eight tunnels close to circular. So, I looked for a higher-level procedural model that comprises circular tunnels as one of its basic primitives, accompanied by a convenient user interface to appropriately scale each tunnel and to place them snuggly next to one another at the desired rotation and tilt angles.

Figure 14 shows such a procedural model, positioning eight partial toroids into a flexible chain. I did not use complete rings, because the walls between adjacent tunnels must be a single shared surface, rather than two almost coinciding surfaces contributed by two adjacent toroids. The missing connectivity between the open gap in one toroid and the ends of the adjacent one were then established in an interactive editing session in NOME.

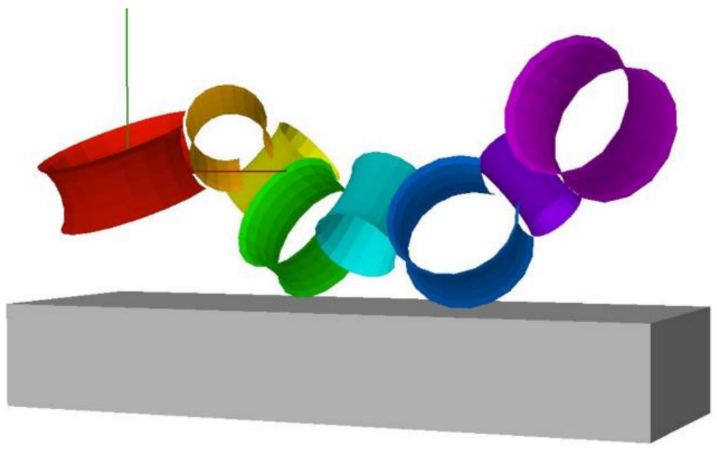

(a)

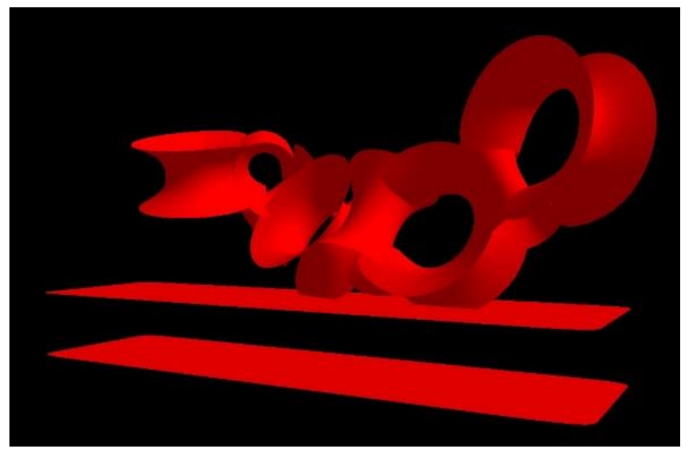

(b)

Figure 14. A procedural model of Hild's Wholly: (a) eight toroidal elements in appropriate positions;

(b) smoothed model after linking the building blocks.

But even this remaining gluing-operation was relatively tedious and did not immediately lead to the smooth saddles found in Hild's sculptures. Thus, in a further iteration, I focused on these saddle elements. I defined a procedural model for a saddle geometry in which I could vary the two principal curvatures individually (Figure 15a). Now the gluing operations can be done between the four open ends of two adjacent saddles. This operation now takes place in a more open space, and it was thus less difficult to produce nice, smooth transitions (Figure 15b). 


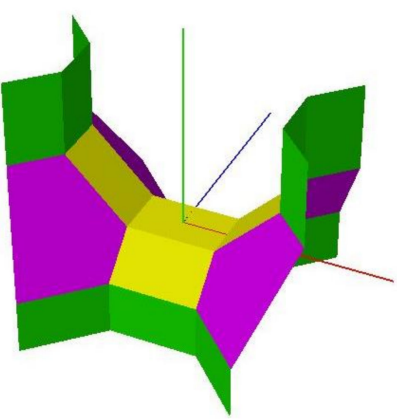

(a)

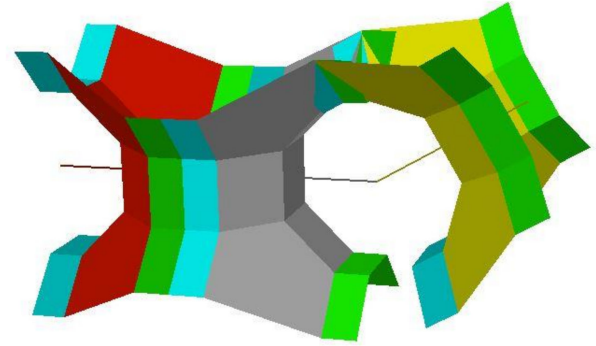

(b)

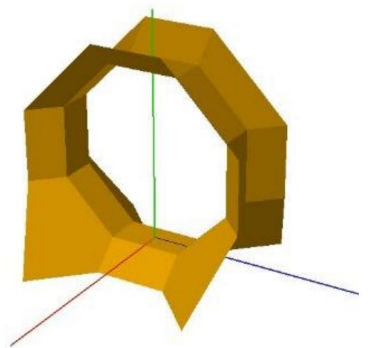

(c)

Figure 15. A procedural saddle model: (a) the basic element, (b) a chain of three elements, and (c) the end module.

For added expediency, I also introduced a special end module, consisting of a complete, well-formed toroid with a single saddle connector on one side (Figure 15c). This then allowed me to obtain a reasonably good match with the original sculpture.

\section{Introducing a Möbius Rim}

With a reasonable modeling technique in hand, I will now focus on topological issues in Hild's sculptures. Most of her sculptures seem to be two-sided. I have not yet found a picture of one that is clearly single-sided; but it is difficult to analyze the more complex ceramic pieces from just one or two images. This prompted me to try to construct some Hild-like 2-manifolds that are single-sided and non-orientable-like a Möbius band or a Klein bottle.

A first approach is derived from the Sue-Dan-ese Möbius band (Figure 16a) [66]. It has a single circular border connected to a roughly spherical bag. But it does not look very Hild-like; its rim does not resemble a funnel, and part of it is obscured by the geometry of its bag-shaped body. Thus, I extend the circular rim into a loopy figure-8-shape, letting the border follow the tangential pull of the attached surface (Figure 16b). This leads to an undulating 3D border curve that is more akin to what is found in Hild's sculptures. In Figure 16c, this new Möbius rim (red) is combined with a bottom funnel (blue) on which the sculpture may rest stably; in addition, part of the connecting mesh is shown in green. Figure 16d shows the resulting smooth, single-sided surface.

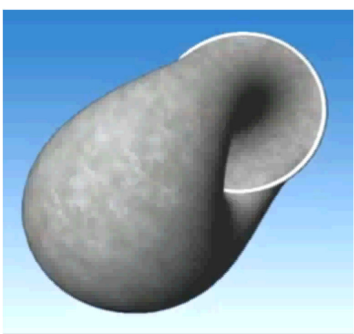

(a)

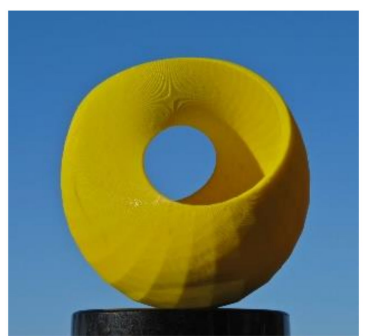

(b)

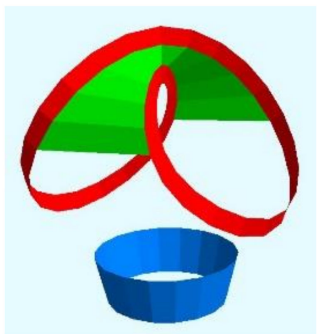

(c)

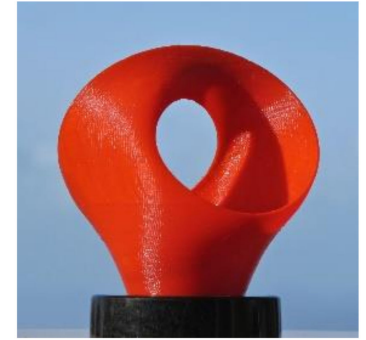

(d)

Figure 16. (a) The Sudanese Möbius band [66]; (b) relaxing the rim into a 3D figure-8 shape; (c) the key features: Möbius rim plus bottom funnel; (d) the resulting single-sided surface.

In a related experiment, I tried to make a single-sided version of Hild's Interruption. With this goal in mind, I replaced the bent oval border loop of Interruption with a stretched version of the Möbius rim (Figure 16c), and I used the same internal combination of three tunnels as in Figure 8b. Figure 17a shows the skeleton formed by these key features and a few initial connecting faces (shown in red). NOME made it easy to add all the other facets to form the complete connecting mesh (Figure 17b). Two steps of subdivision already form a nice, smooth surface (Figure 17c). Figure $17 \mathrm{~d}$ shows the resulting $3 \mathrm{D}$ printed model. 


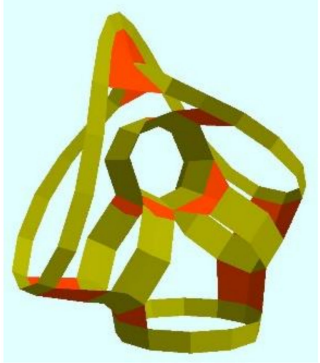

(a)

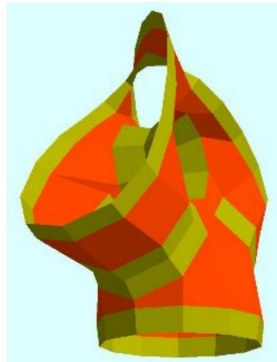

(b)

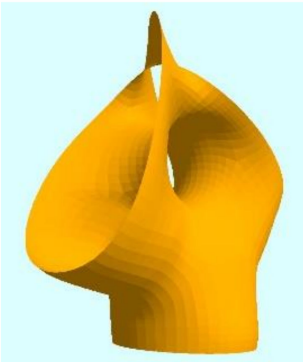

(c)

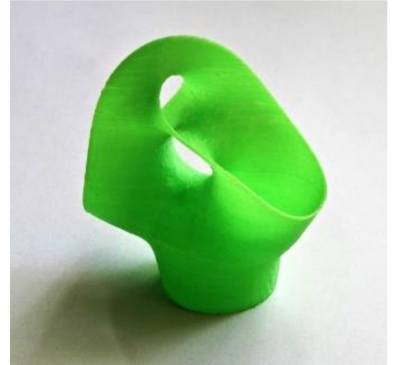

(d)

Figure 17. Modeling Single-Sided Interruption: (a) a skeleton with a Möbius ribbon on top; (b) the connecting mesh; (c) the subdivision surface; (d) a resulting 3D printed model.

\section{Rings of Dyck's Disks}

Another approach to generate a non-orientable surface starts with a single circular disk from which two tubular stubs emerge in opposite directions (Figure 18a); this is known as Dyck's surface [67]. If these two stubs are joined together with a toroidal loop, one obtains a single-sided 2-manifold (Figure 18b). However, such a prominent toroidal handle is not a typical occurrence in Hild's artwork. Thus, I replaced the toroidal handle by inserting additional Dyck disks into the loop (Figure 18c,d). Any such loop formed by an odd number of disks will result in a single-sided 2-manifold.

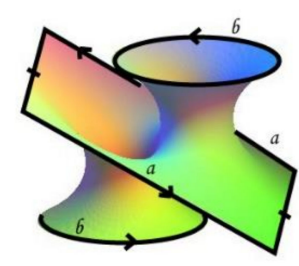

(a)

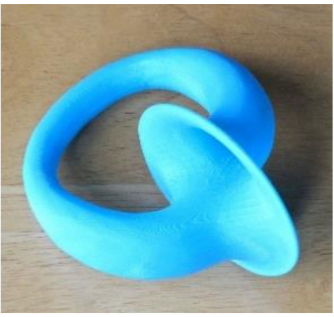

(b)

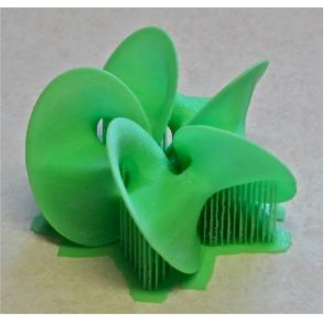

(c)

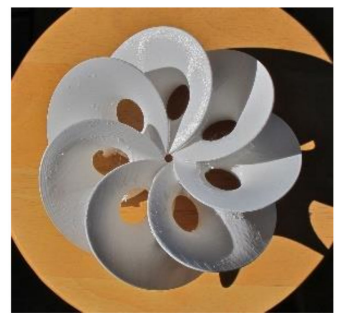

(d)

Figure 18. (a) Dyck's surface; (b) with a toroidal loop added; (c) five disks in a circuit; (e) seven Dyck disks in a circuit.

Eva Hild typically avoids rigid symmetry and makes the tunnels and lobes in a sculpture of somewhat different sizes (Figure 9a,b). Thus, in Figure 19, I scaled subsequent instances of Dyck's disks by $10 \%$ and let this logarithmic spiral sweep through only $300^{\circ}$. The remaining $60^{\circ}$ are then filled with a bulbous element (as found in some of Hild's sculptures), which in this case, is a convenient way to connect the two tubular stubs of rather different diameters. This sculpture was exhibited at the Bridges 2017 Mathematical Art Gallery [68].

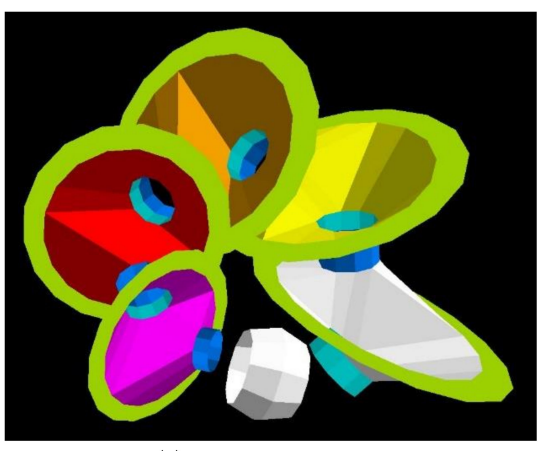

(a)

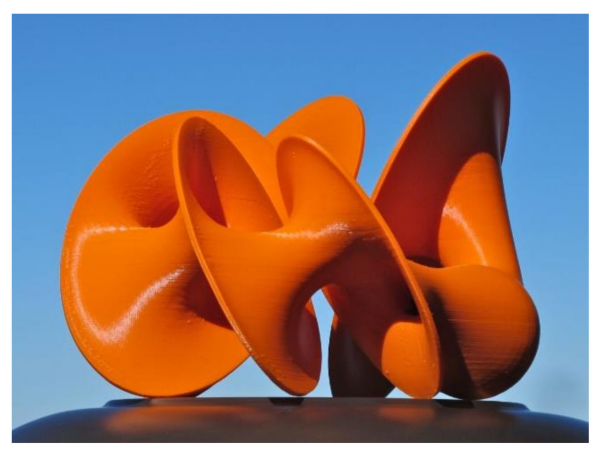

(b)

Figure 19. Five Dyck disks of different sizes connected into a loop: (a) the placement of the defining key features and part of the connecting mesh; (b) the resulting 3D printed model [68]. 


\section{Dyck Clusters of Higher Genus}

The Dyck disk has only two tubular connectors, so it can form only open chains or simple loops. Therefore, I created a modification with two stubs emerging from either side of the disk. Now we have a valence-4 element that can realize more intricately connected graphs. A single Dyck disk with the stubs emerging from the same side connected to one another, yields a two-sided surface (Figure 20a). If, instead, loops are formed between stubs emerging from opposite sides, a non-orientable surface results (Figure 20b). In Figure 20c, four disks have been connected in a symmetrical manner to form an orientable, two-sided surface.

In the following constructions, I have moved in the opposite direction of where Eva Hild would be going; I have aimed to maximize symmetry as well as the connectivity of my 2-manifolds. To obtain a high degree of symmetry, I start with the symmetries of the Platonic solids. In Figure 21a, I have placed six 4-stub Dyck disks at the edge-midpoints of a tetrahedron. I then interconnected groups of six stubs that point towards the same tetrahedron vertex so that they form a 3-branch ring, reminiscent of a truncated corner. In Figure 21b,c, I apply the same process to an octahedron. In these latter figures, we are looking down onto a truncated valence- 4 corner. The genus of these surfaces is always one higher than the number of disks, and every rim of a disk represents a topological "puncture" in these 2-manifolds.

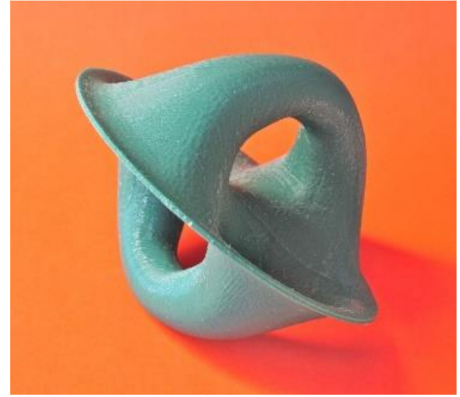

(a)

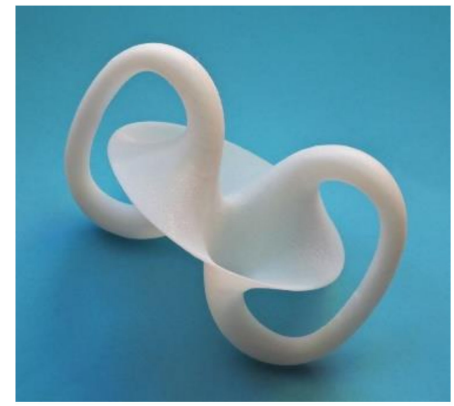

(b)

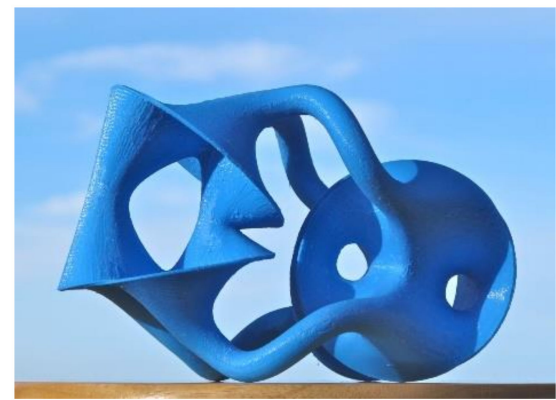

(c)

Figure 20. Dyck disks with four stubs: (a) local connections resulting in a two-sided surface; (b) local connections forming a one-sided surface; (c) four disks forming a two-sided surface.

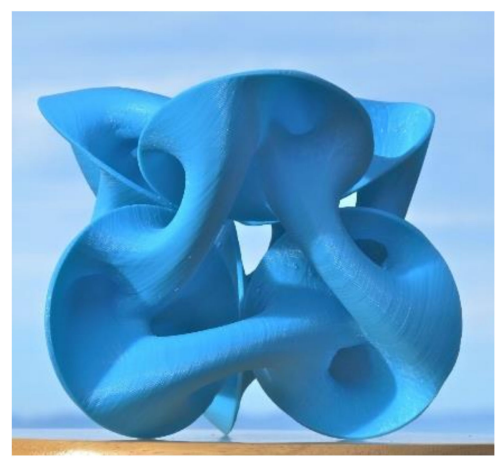

(a)

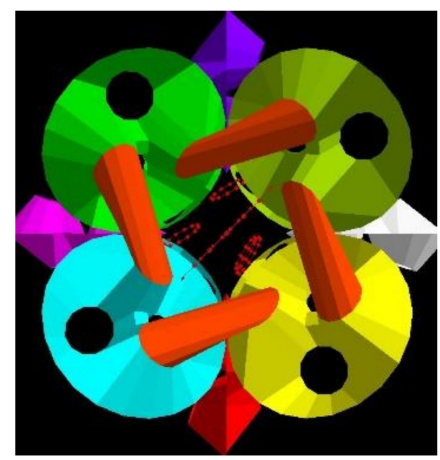

(b)

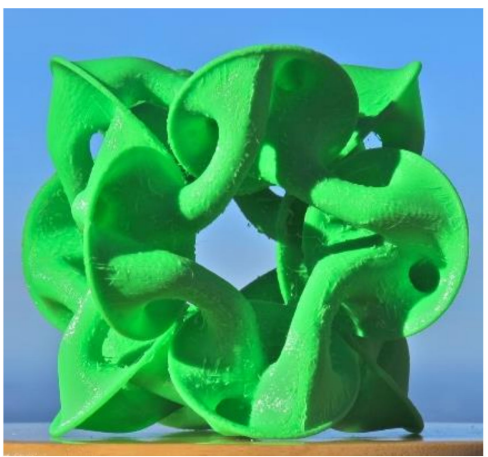

(c)

Figure 21. Clusters of 4-stub Dyck disks: (a) 6 disks in tetrahedral symmetry; (b) 12 disks in octahedral symmetry: CAD model; (c) octahedral 3D printed model.

In Figure 22a, twelve 4-stub Dyck disks have been placed at the mid-edge points of a cube; here we are looking at one of the original cube faces. Finally, in Figure 22b, 24 disks have been placed perpendicularly to the edges of a rhombic dodecahedron. The result is a single-sided surface of genus 25 with 24 punctures. It has been exhibited at the JMM 2018 Mathematical Art Gallery [69]. 


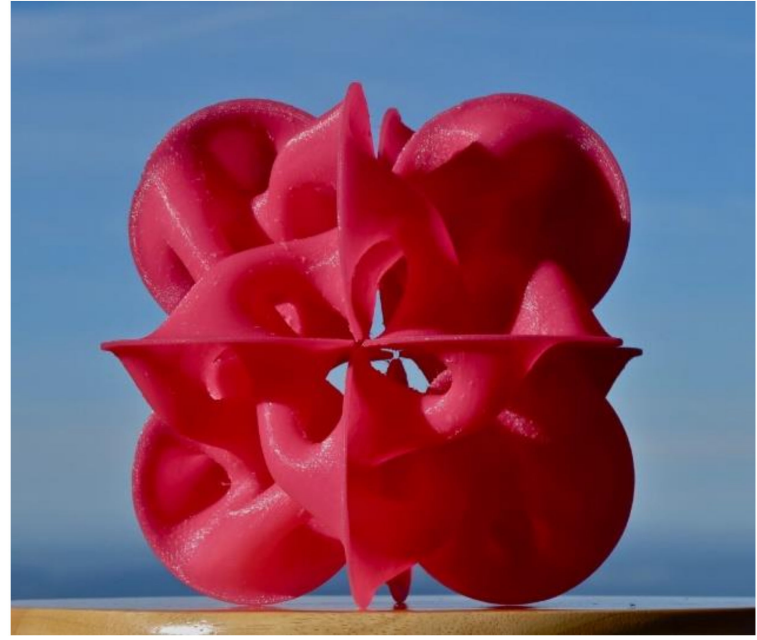

(a)

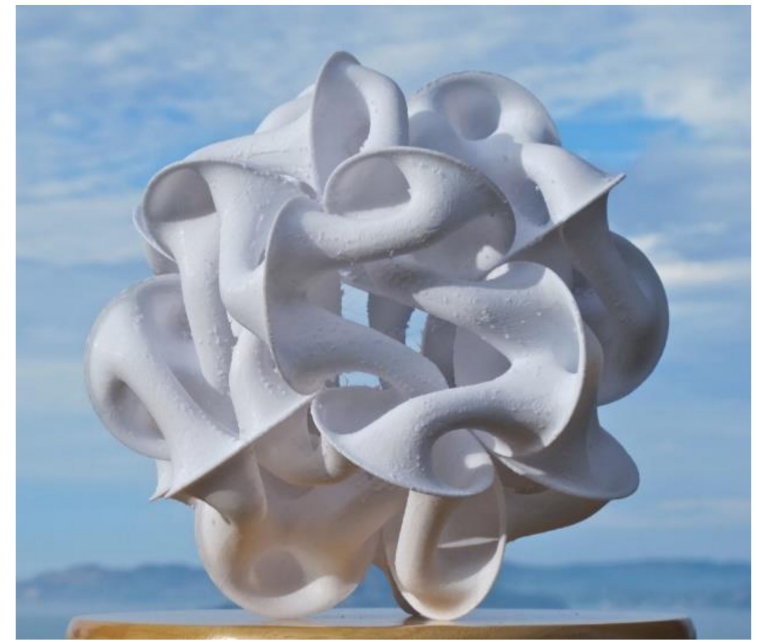

(b)

Figure 22. Platonic Dyck clusters: (a) based on cubic symmetry; (b) based on rhombic dodecahedron symmetry [69].

\section{Discussion and Conclusions}

In my modeling efforts assisted by CAD tools, I start with the placement of border curves and other defining features, and then I fill in surface patches between them (Figure 17 and Figure 19). Alternatively, I may place modular surface elements, so that some of their borders coincide and then merge them into a single cohesive 2-manifold (Figures 21 and 22 ). Eva Hild, on the other hand, conveyed to me, in my visit to her studio, that she mostly thinks about spaces. Her ceramic surfaces serve to define those spaces and to separate adjacent spaces. She may start with some bowl-shaped surface or some cylindrical wall and then gradually grow that surface in an organic manner. In this process, the surface may form funnels or bulbous outgrowths. Tunnels may split into two or more branches and then recombine in different ways, and border curves may warp into sensuous undulations.

Twisted ribbons are not natural elements for defining spaces, so they are not typically found in Hild's sculptures. Tubular loops, starting and ending on different sides of the same surface patch, as in Dyck's disk (Figure 18b), would be another way to produce single-sided surfaces. Such loops rarely show up in her 2-manifold sculptures. Thus, it took some effort to introduce non-orientable surface constructs into my models, while hiding them, so that the result does not immediately stand out as something that one would not find in Hild's studio.

Our emerging NOME modeling environment [62] makes the design process for 2-manifold sculptures in the style of Eva Hild manageable, even though it is still very much in the development stage. It is particularly convenient and powerful for geometries with a high degree of symmetry.

On the other hand, it is unlikely that with our current approach I will ever create something approximating the fluid, natural beauty of Hild's sculptures. Eva explained to me that her pieces grow slowly and organically. She has an initial idea and a starting point, but this will then change and develop gradually during a process, which may take months or even years. She is often surprised when she looks at the resulting final sculpture and wonders: "Where did that shape come from?"

In contrast, my own computer-based approach is much more "top-down." I start with a well-defined plan, and specify the overall symmetry that I want to maintain. The use of symmetry significantly reduces the amount of detailed design work that I have to do. Moreover, the use of computer-aided procedures allows me to create structures of a complexity that would be difficult to achieve in a gradual, bottom-up approach. While my own creations may have a quite different look-and-feel to them, I still would like to thank Eva Hild—and many other "intuitive" artists—for the inspiration they provide. 
Funding: This research received no external funding.

Acknowledgments: I would like to thank the staff of the Jacobs Institute for Design Innovation at UC Berkeley for their help in fabricating many of the sculptural models presented.

Conflicts of Interest: The author declares no conflict of interest.

\section{References}

1. Hild, E. EVA HILD (Home Page). Available online: http:// evahild.com/ (accessed on 12 January 2019).

2. Friedman, N.A. Eva Hild: Topological Sculpture from Life Experience. In Proceedings of the Bridges Conference, London, UK, 4-8 August 2006; pp. 569-572. Available online: http:/ /archive.bridgesmathart. org/2006/bridges2006-569.html (accessed on 12 January 2019).

3. Friedman, N.A. Eva Hild: Sculpture and Light. Hyperseeing, August 2007; pp. 3-6. Available online: http:/ / www.isama.org/hyperseeing/07/07-08.pdf (accessed on 12 January 2019).

4. Séquin, C.H. Homage to Eva Hild. In Proceedings of the Bridges Conference, Waterloo, ON, Canada, 27-31 July 2017; pp. 117-124. Available online: http:/ / archive.bridgesmathart.org/2017/bridges2017-117.html (accessed on 12 January 2019).

5. Home of the Blender Project. Available online: https://www.blender.org/ (accessed on 12 January 2019).

6. Maya, Computer Animation \& Modeling Software. Available online: https://www.autodesk.com/products/ maya/overview (accessed on 12 January 2019).

7. Séquin, C.H. Creative Geometric Modeling with UNIGRAFIX. UCB Technical Report No. UCB/CSD-83-162, December 1983. Available online: http:/ / www2.eecs.berkeley.edu/Pubs/TechRpts/1983/CSD-83-162.pdf (accessed on 12 January 2019).

8. Collins, B. Sculpture Pictures. Bridges Virtual Museum. Available online: http://bridgesmathart.org/ bcollins/bcollins.html (accessed on 12 January 2019).

9. Francis, G.K. On Knot-Spanning Surfaces: An Illustrated Essay on Topologial Art. With an Artist's Statement by Brent Collins. Leonardo J. 1992, 25, 313-320. [CrossRef]

10. Séquin, C.H. Virtual Prototyping of Scherk-Collins Saddle Rings. Leonardo J. 1997, 30, 89-96. Available online: https:/ / muse.jhu.edu/article/607427/pdf (accessed on 12 January 2019). [CrossRef]

11. Séquin, C.H. Sculpture Design. In Proceedings of the 7th International Conference on Virtual Systems and Multimedia (VSMM'01), Washington, DC, USA, 25-27 October 2001; Available online: http:/ / people.eecs. berkeley.edu/ \{\}sequin/PAPERS/VSMM01_Sculpt.pdf (accessed on 12 January 2019).

12. Séquin, C.H. Part Description and Specifications for "Heptagonal Toroid". Available online: https://people. eecs.berkeley.edu/ \{\}sequin/SFF/spec.heptoroid.html (accessed on 12 January 2019).

13. Scherk's Second Minimal Surface. Wikipedia. Available online: https://en.wikipedia.org/wiki/Scherk_ surface\#/media/File:Scherk\%27s_second_surface.png (accessed on 12 January 2019).

14. Séquin, C.H. Part Description and Specifications for "Pax Mundi". Available online: https:// people.eecs. berkeley.edu/ \{\}sequin/SCULPTS/CHS_bronzes/paxmundi.html (accessed on 12 January 2019).

15. Smith, J. SLIDE Design Environment. 2003. Available online: http://www.cs.berkeley.edu/ \{\}ug/slide/ (accessed on 12 January 2019).

16. Séquin, C.H. Viae Globi-Pathways on a Sphere. Proceedings M+D 2001, Geelong, Australia, July 2001. Available online: http://people.eecs.berkeley.edu/ \{\}sequin/PAPERS/MD2001_ ViaeGlobi.pdf (accessed on 12 January 2019).

17. Reinmuth, S. Reinmuth Bronze Studio, Inc. Available online: http://www.reinmuth.com/ (accessed on 12 January 2019).

18. Séquin, C.H. Art, Geometry, and Abstract Sculpture, Figure 1, PAX MUNDI. Available online: https:/ / www2.eecs.berkeley.edu/Research/Projects/Data/270.html (accessed on 12 January 2019).

19. Séquin, C.H. The Beauty of Knots, Figure 5b, Collins' "Music of the Spheres" (with Steve Reinmuth and Brent Collins). Available online: https:/ / people.eecs.berkeley.edu/ \{\}sequin/CS39/TEXT/BeautyOfKnots.pdf (accessed on 12 January 2019).

20. Ferguson, C. Helaman Ferguson: Mathematics in Stone and Bronze; Meridian Creative Group: Erie, PA, USA, 1994.

21. Ferguson, H. Topological Design of Sculptured Surfaces. Comput. Graph. 1992, 26, 149-156. Available online: http:/ / papers.cumincad.org/data/works/att/2b7a.content.pdf (accessed on 12 January 2019). [CrossRef] 
22. Hart, G.W. Geometric Sculpture (Home Page). Available online: https://www.georgehart.com/sculpture/ sculpture.html (accessed on 12 January 2019).

23. Hart, G.W. Icosahedral Constructions. In Proceedings of the Bridges Conference, Winfield, KS, USA, 28-30 July 1998; pp. 195-202. Available online: http:/ / archive.bridgesmathart.org/1998/bridges1998-195.pdf (accessed on 12 January 2019).

24. Hart, G.W. Sculpture from Symmetrically Arranged Planar Components. In Proceedings of the Bridges Conference, Granada, Spain, 23-26 July 2003; pp. 315-322. Available online: http:/ / archive.bridgesmathart. org/2003/bridges2003-315.html (accessed on 12 January 2019).

25. Hart, G.W. Modular Kirigami. In Proceedings of the Bridges Conference, San Sebastian, Spain, 24-27 July 2007; pp. 1-8. Available online: http://archive.bridgesmathart.org/2007/bridges2007-1.html (accessed on 12 January 2019).

26. Grossman, B. Bathsheba Sculpture. (Home Page). Available online: https://bathsheba.com/ (accessed on 12 January 2019).

27. Bulatov, V. Bulatov Abstract Creations. (Home Page). Available online: http://bulatov.org/ (accessed on 12 January 2019).

28. Roelofs, R. Sculpture. (Home Page). Available online: http:/ / www.rinusroelofs.nl/sculpture/sculpture-00.html (accessed on 12 January 2019).

29. Schepker, H. Glass Geometry. (Home Page). Available online: https://glassgeometry.com/intro.html (accessed on 12 January 2019).

30. Perry, C.O. Selected Works 1964-2011; The Perry Sudio: Norwalk, CT, USA, 2011.

31. Perry, C.O.; Charles, O. PERRY (Home Page). Available online: http://www.charlesperry.com/ (accessed on 12 January 2019).

32. Perry, C.O. On the Edge of Science: The Role of the Scientist's Intuition in Science. Leonardo J. 1992, 25, $249-252$. [CrossRef]

33. Perry, C.O. Art and the Age of the Sciences. In The Visual Mind II; Emmer, M., Ed.; MIT Press: Cambridge, MA, USA, 2005; pp. 235-252.

34. Van Wijk, J.J;; Cohen, A.M. Visualization of Seifert Surfaces. IEEE Trans. Vis. Comput. Graph. 2006, 12, 485-496. Available online: https:/ /ieeexplore.ieee.org/abstract/document/1634314 (accessed on 12 January 2019). [CrossRef] [PubMed]

35. Van Wijk, J.J. Seifertview. Available online: http://www.win.tue.nl/ \{\}vanwijk/seifertview/ (accessed on 12 January 2019).

36. Apéry, F. Boy's Surface (Apery). Available online: http://xahlee.info/surface/boys_apery/boys_apery.html (accessed on 12 January 2019).

37. Séquin, C.H. Cross-Caps-Boy Caps-Boy Cups. In Proceedings of the Bridges Conference, Enschede, The Netherlands, 27-31 July 2013; pp. 207-216. Available online: http://archive.bridgesmathart.org/ 2013/bridges2013-207.html (accessed on 12 January 2019).

38. Grossmann, B. The Klein Bottle Opener. Available online: https://bathsheba.com/math/klein/ (accessed on 12 January 2019).

39. Séquin, C.H. On the Number of Klein Bottle Types. J. Math. Arts 2013, 7, 51-63. Available online: http:/ / people. eecs.berkeley.edu/ \{\}sequin/PAPERS/2013_JMA_Klein-bottles.pdf (accessed on 12 January 2019). [CrossRef]

40. Jarke, J.; van Wijk, J.J. Symmetric tiling of closed surfaces: Visualization of regular maps. ACM Trans. Graph. (TOG) 2009, 28, 49. Available online: https:/ /dl.acm.org/citation.cfm?id=1531355 (accessed on 12 January 2019).

41. Razafindrazaka, F.H.; Polthier, K. Regular Surfaces and Regular Maps. In Proceedings of the Bridges Conference, Seoul, Korea, 14-19 August 2014; pp. 225-234. Available online: http:/ / archive.bridgesmathart. org/2014/bridges2014-225.html (accessed on 15 January 2019).

42. Razafindrazaka, F.H.; Polthier, K. Realization of Regular Maps of Large Genus. In Topological and Statistical Methods for Complex Data; Springer: Berlin/Heidelberg, Germany, 2015; pp. 239-252. Available online: https://pdfs. semanticscholar.org/042d/21622fe7f4314e655b10b9f5f0e40be0f151.pdf (accessed on 15 January 2019).

43. Akleman, E.; Chen, J. Regular Meshes. In Proceedings of the 2005 ACM Symposium on Solid and Physical Modeling, Cambridge, MA, USA, 13-15 June 2005; pp. 213-219. Available online: https://dl.acm.org/ citation.cfm?id=1060268 (accessed on 15 January 2019).

44. Akleman, E.; Chen, J. Regular Mesh Construction Algorithms Using Regular Handles. In Proceedings of the IEEE International Conference on Shape Modeling and Applications, Matsushima, Japan, 14-16 June 2006; Available online: https:/ /ieeexplore.ieee.org/abstract/document/1631206 (accessed on 15 January 2019). 
45. Akleman, E.; Chen, J.; Xing, Q.; Gross, J.L. Cyclic Plain-Weaving on Polygonal Mesh Surfaces with Graph Rotation Systems. ACM Trans. Graph. (TOG) 2009, 28, 78-1-78-8. Available online: http://citeseerx. ist.psu.edu/viewdoc/download?doi=10.1.1.378.5899\&rep=rep1\&type=pdf (accessed on 15 January 2019). [CrossRef]

46. Akleman, E.; Chen, J.; Chen, Y.L.; Xing, Q.; Gross, J.L. Cyclic Twill-Woven Objects. Comput. Graph. 2011, 35, 623-631. Available online: https:/ / www.sciencedirect.com/science/article/pii/S0097849311000422 (accessed on 15 January 2019). [CrossRef]

47. Friedman, N.A. Hyperseeing, Hypersculptures, Knots, and Minimal Surfaces. Available online: https:/ / www.mi.sanu.ac.rs/vismath/nat/index.html (accessed on 15 January 2019).

48. Séquin, C.H. Tangled Knots. In Proceedings of the "Art + Math = X" International Conference, Boulder, CO, USA, 2-5 June 2005; pp. 161-165. Available online: https:/ / people.eecs.berkeley.edu/ \{\}sequin/PAPERS/ ArtMath05_TangledKnots.pdf (accessed on 12 January 2019).

49. Séquin, C.H. Splitting Tori, Knots, and Moebius Bands. In Proceedings of the Bridges Conference, Banff, AB, Canada, 31 July-3 August 2005; pp. 211-218. Available online: http:/ / archive.bridgesmathart.org/2005/ bridges2005-211.html (accessed on 15 January 2019).

50. Akleman, E.; Yuksel, C. On a Family of Symmetric, Connected and High Genus Sculptures. In Proceedings of the Bridges Conference, London, UK, 4-8 August 2006; pp. 145-150. Available online: https: / archive. bridgesmathart.org/2006/bridges2006-145.pdf (accessed on 15 January 2019).

51. Séquin, C.H. Sculpture Designs Based on Borromean Soap Films. UCB Tech Report (EECS-2018-192), December 2018. Available online: https:/ /www2.eecs.berkeley.edu/Pubs/TechRpts/2018/EECS-2018-192.html (accessed on 15 January 2019).

52. Wikipedia. Rhinoceros 3D. Available online: https://en.wikipedia.org/wiki/Rhinoceros_3D (accessed on 15 January 2019).

53. Akleman, E. TopMod-Topological Mesh Modeling. Available online: http://people.tamu.edu/ \{\}ergun/ research/topology/index.html (accessed on 15 January 2019).

54. Friedman, N.A.; Séquin, C.H. Keizo Ushio's Sculptures, Split Tori and Möbius Bands. J. Math. Arts 2007, 1, 47-57. Available online: https:/ / www.tandfonline.com/doi/abs/10.1080/17513470701217217 (accessed on 15 January 2019). [CrossRef]

55. Longhurst, R. Robert Longhurst Studio. Available online: http://www.robertlonghurst.com/ (accessed on 15 January 2019).

56. Wills, T. D-Forms: 3D forms from two 2D sheets. In Proceedings of the Bridges Conference, London, UK, 4-8 August 2006; pp. 503-510. Available online: https://archive.bridgesmathart.org/2006/bridges2006-503.html (accessed on 15 January 2019).

57. Akgün, T.; Kaya, I.; Koman, A.; Akleman, E. Developable Sculptural Forms of Ilhan Koman. In Proceedings of the Bridges Conference, London, UK, 4-8 August 2006; pp. 343-350. Available online: http: / /archive. bridgesmathart.org/2006/bridges2006-343.html (accessed on 15 January 2019).

58. Akgün, T.; Kaya, I.; Koman, A.; Akleman, E. Spiral Developable Sculptures of Ilhan Koman. In Proceedings of the Bridges Conference, San Sebastian, Spain, 24-27 July 2007; pp. 47-52. Available online: https:/ / archive.bridgesmathart.org/2007/bridges2007-47.pdf (accessed on 15 January 2019).

59. Séquin, C.H. 2-Manifold Sculptures. In Proceedings of the Bridges Conference, Baltimore, MD, USA, 29 July-2 August 2015; pp. 17-26. Available online: http:/ / archive.bridgesmathart.org/2015/bridges2015-17.html (accessed on 1 January 2019).

60. Hild, E. Interruption. Available online: https://www.bukowskis.com/en/auctions/H043/67-an-eva-hildstoneware-sculpture-interruption-2002 (accessed on 1 January 2019).

61. Wang, Y. Robust Geometry Kernel and UI for Handling Non-Orientable 2-Mainfolds. UCB TechReport (EECS-2016-65), 12 May 2016. Available online: https:/ / www2.eecs.berkeley.edu/Pubs/TechRpts/2016/ EECS-2016-65.html (accessed on 1 January 2019).

62. Dieppedalle, G. Interactive CAD Software for the Design of Free-form 2-Manifold Surfaces. (NOME). UCB TechReport (EECS-2018-48), 10 May 2018. Available online: https:/ /www2.eecs.berkeley.edu/Pubs / TechRpts / 2018/EECS-2018-48.html (accessed on 1 January 2019).

63. Catmull, E.; Clark, J. Recursively generated B-spline surfaces on arbitrary topological meshes. Comput. Aided Des. 1978, 10, 350-355. [CrossRef] 
64. What Is an STL File? Available online: https:/ / www.3dsystems.com/quickparts/learning-center/what-is-stl-file (accessed on 1 January 2019).

65. Séquin, C.H. Shape Representation: “Gabo Curve.” (Slide 36). Available online: http:/ / slideplayer.com/ slide/9035370/ (accessed on 1 January 2019).

66. Asimov, D.; Lerner, D. Sudanese Möbius Band. Issue 17, SIGGRAPH '84: Electronic Theater. Available online: https:/ / search.library.brown.edu/catalog/b7650865 (accessed on 24 January 2019).

67. Dyck Surface. Available online: http://www.mathcurve.com/surfaces/dyck/dyck.shtml (accessed on 12 January 2019).

68. Séquin, C.H. Pentagonal Dyck Cycle. Available online: http://gallery.bridgesmathart.org/exhibitions/2017bridges-conference/sequin (accessed on 1 January 2019).

69. Séquin, C.H. Dodecahedral-Cluster of 25 Klein-Bottles. Available online: http:/ /gallery.bridgesmathart.org/ exhibitions /2018-joint-mathematics-meetings/sequin (accessed on 12 January 2019).

(C) 2019 by the author. Licensee MDPI, Basel, Switzerland. This article is an open access article distributed under the terms and conditions of the Creative Commons Attribution (CC BY) license (http:/ / creativecommons.org/licenses/by/4.0/). 